\title{
The Design of Cruciform Test Specimens for Planar Biaxial Testing of Fabrics for Inflatable Aerodynamic Decelerators
}

\author{
C. Corbin \\ NASA Langley Research Center, Structural Mechanics and Concepts Branch, Mail \\ Stop 190, 8 W. Taylor St., Hampton, VA 23681; Ph (757) 864-8874; email: \\ cole.corbin@nasa.gov
}

\begin{abstract}
A preliminary analytical study was conducted to investigate the effects of cruciform test specimen geometries on strain distribution uniformity in the central gage section under biaxial loads. Three distinct specimen geometries were considered while varying the applied displacements in the two orthogonal directions. Two sets of woven fabric material properties found in literature were used to quantify the influence of specimen geometries on the resulting strain distributions. The uniformity of the strain distribution is quantified by taking the ratio between the two orthogonal strain components and characterizing its gradient across the central area of the gage section. The analysis results show that increasing the specimen's length relative to its width promotes a more uniform strain distribution in the central section of the cruciform test specimen under equibiaxial enforced tensile displacements. However, for the two sets of material properties used in this study, this trend did not necessary hold, when the enforced tensile displacements in the two orthogonal directions were not equal. Therefore, based on the current study, a tail length that is 1.5 times that of the tail width is recommended to be the baseline/initial specimen design.
\end{abstract}

\section{INTRODUCTION}

The National Aeronautics and Space Administration (NASA) had been heavily involved in research and development efforts using soft goods, i.e. space structures constructed from flexible materials. NASA's Hypersonic Inflatable Aerodynamic Decelerator project currently has a task at Langley Research Center (LaRC) characterizing the mechanical properties of the various fabric systems that are intended to be used in the construction of the inflatable decelerators. One fabric testing methodology currently under development is the planar biaxial tensiontension test. The objective of the test is to measure the mechanical properties of coated plain-weave fabrics, such as Kevlar ${ }^{\circledR}$ laminated with Kapton ${ }^{\circledR}$, that are part of the decelerators' thermal protection system.

To adequately characterize the fabric's mechanical properties (stiffness and strength) the material needs to be bi-axially loaded at various load ratios between the two orthogonal loading directions. Designing a cruciform test specimen for biaxial 
testing can be a challenge for woven fabric materials. Unlike rigid materials, such as metals and traditional composites, where the cruciform specimen's thickness can be gently tapered and adjusted in the central gage section or fillets can be machined at the junctions where the four "tails" of the specimen meet, fabrics cannot be easily tailored to have a uniform stress/strain distribution. This paper summarizes a preliminary analytical design study conducted at LaRC to determine test specimen geometries that will best lead to uniform strain distribution in the test section of a biaxially-loaded, woven fabric cruciform test article.

\section{APPROACH}

A preliminary analytical design study was used to quantify the influence of the geometric parameters on the uniformity of the stress and strain distribution of cruciform specimens. The results of this study can be used to aid in the design of woven fabric cruciform specimen geometries for experimental testing. An appropriate test setup (fixtures, etc.) can then be configured to accommodate the specimen geometry. For this study, three distinct geometries were considered along with two sets of woven fabric material properties found in the literature, under three planar biaxial loading conditions. The Abaqus finite element modeling and analysis software (Dassault Systémes, 2011) was used to model and analyze the various combinations of geometry, material, and loading conditions. Woven fabrics typically exhibit highly non-linear characteristics under load, but this initial effort was conducted assuming linear elastic properties to simplify the analysis.

It could be considered a paradoxical approach to study the strain distribution in woven fabric cruciform specimens by running analytical simulations of biaxial tests by using a set of assumed material properties, when the purpose of the experimental biaxial tests is to characterize the properties of the material. However, this study still offers some insight into how best to size such specimens. The assumed properties can be used to assess whether or not a specific specimen design could provide an adequate zone of uniform stress distribution in its center. The results can be used to initially configure the various hardware components that are needed in an experimental test setup. Additionally, this information can be used to estimate the total amount of material needed to adequately characterize a material system, i.e. develop a test matrix.

\section{GEOMETRIC PARAMETERS}

Specimens with varying $\mathrm{L} / \mathrm{W}$ ratios (the ratio between the length of the tail section from the center of the specimen to the grip, L, and the width of the tail section, W) have been tested in the past. Klein (1959) reports that to ensure that a small central region in the specimen is under a uniform biaxial strain state, the opposing sets of grips must be sufficiently spaced apart as to minimize the boundary effects due to the clamping on the ends. Figure 1 shows several examples of cruciform test specimen 
geometries found in the literature including the segmented tail design (Figure 1d) considered by Kawabata et al. (1973), Reinhardt (1976), Ghosh (1999), and others. The segmented tail design, not under consideration in this study, requires a complex gripping scheme at the ends, and allows the specimen's clamped ends to move in the direction perpendicular to the loading direction, thus minimizing boundary effects (Ghosh, 1999).

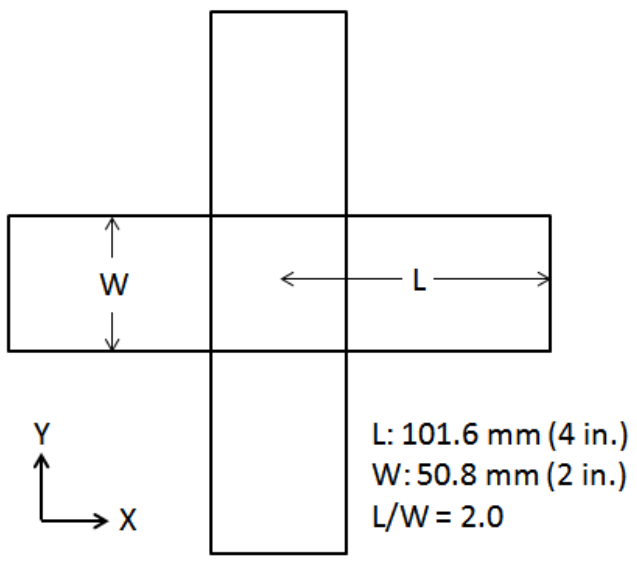

(a) Lindell et al. (2006) and Hinkle (2010)

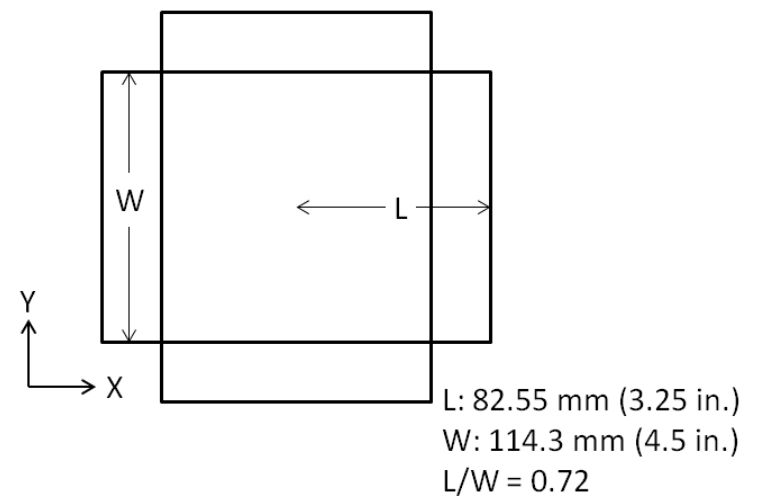

(c) Cavallaro et al. (2007)

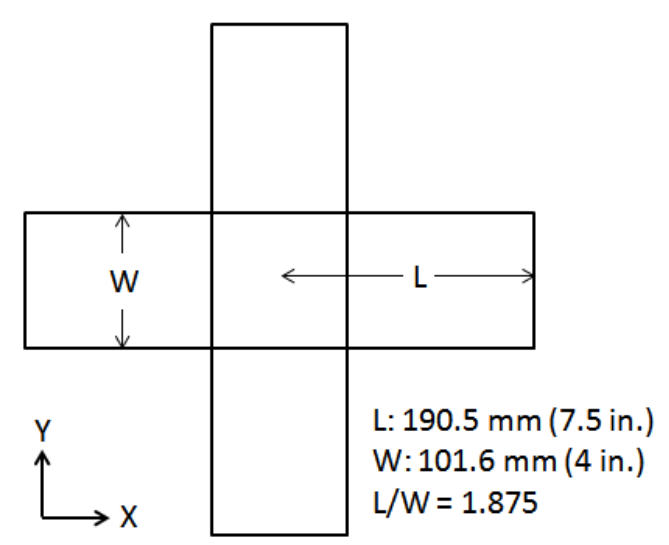

(b) Freeston et al. (1967)

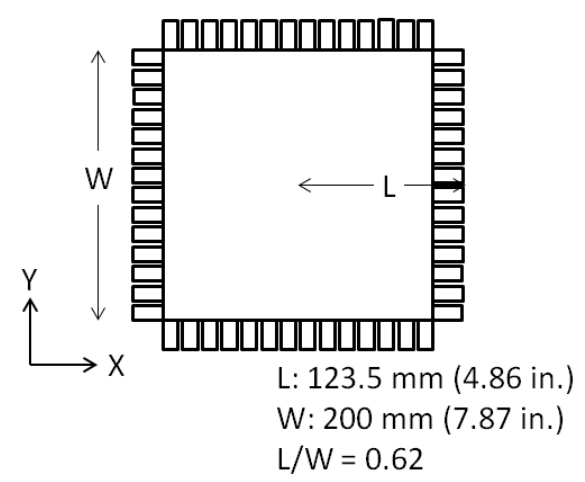

(d) Ghosh (1999)

Figure 1. Various cruciform geometries and their $\mathrm{L} / \mathrm{W}$ ratios.

Given a central square area where the four tails intersect, having a dimension of Wby-W, the desire is to have a portion of that area under a uniform strain (Freeston et al., 1967). In this study, the goal was to quantify the uniformity of the strain distribution in the central W/2-by-W/2 zone, as shown by the dashed boxes on Figure 2 , for varying $\mathrm{L} / \mathrm{W}$ ratios. Three values for the ratio between the length of the tail section, $\mathrm{L}$, and the width of the tail section, $\mathrm{W}$, were considered. 


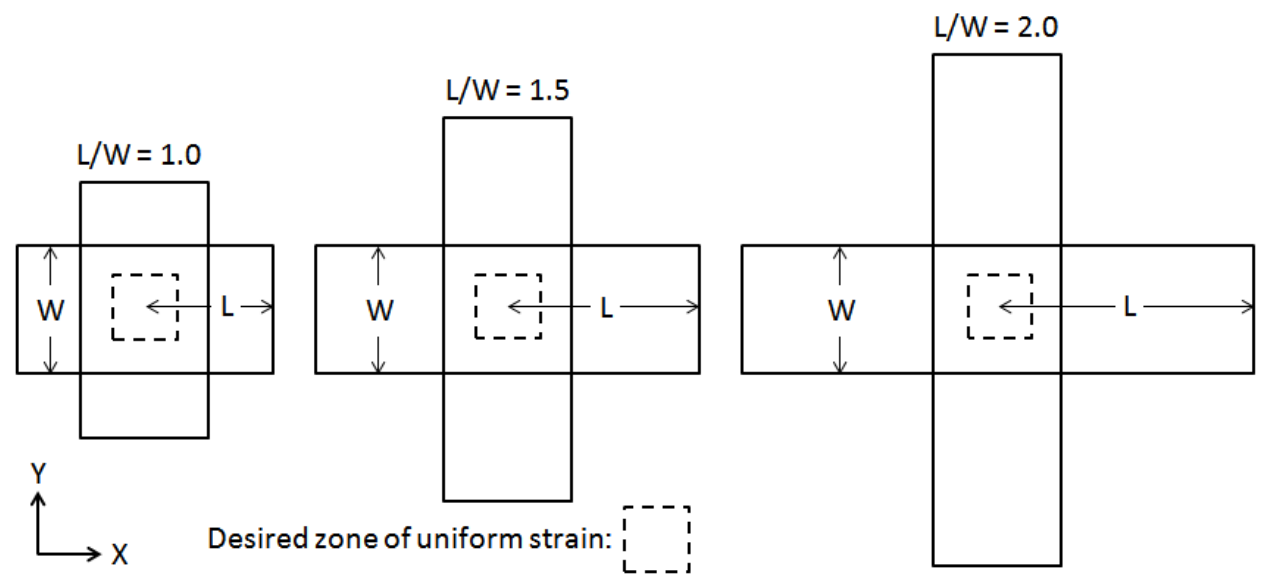

Figure 2. Cruciform geometries with three $\mathrm{L} / \mathrm{W}$ ratios considered.

\section{ASSUMED MATERIAL PROPERTIES}

A literature survey yields numerous sources of experimental data on woven fabric's mechanical properties. For example, Sebring et al. (1969) published data for polyurethane and vinyl coated nylon fabric from planar biaxial tension-tension tests, and Cavallaro et al. (2007) and Ghosh (1999) published stress-strain curves for uncoated plain-woven polyester fabric under biaxial loads. Among the data sets found, only a select few were directly applicable to the current study. Specifically, Hutchings et al. (2009) and Lin et al. (2010) presented the stiffness properties of coated Kevlar® materials.

Woven fabrics typically exhibit a non-linear stress-strain response under load due to the crimp-interchange that occurs between the warp and fill yarns (Kawabata et al. 1973). Additionally, they have a very complex response to loads where the ratio of the applied loads between the warp and fill directions affect the stiffness as well as the Poisson's Ratio (Bassett et al. 1999). However, in an effort to limit the scope of this initial study, the material properties were assumed to be constant and homogeneous, and applicable in a linearly-elastic finite element model. This assumption is based on the observation that the response of coated fabric systems is bi-linear, where the stiffness curve becomes fairly linear after the initial non-linear de-crimping phase (Testa et al. 1978). Even within the bounds of this limited study, the performance of a cruciform specimen geometry, defined as the level of uniformity of the strain distribution in the central gage section, can be quantified and its sensitivity to a single geometric parameter, L/W, can be compared.

The assumed material properties used in the study are shown in Table 1 . The properties in the table are the estimated biaxial properties, average of the two bilinear regions, per Hutchings et al. (2009), or the linear portion of the stress-strain curves from Lin et al. (2010), respectively. 
Table 1. Assumed Linear Elastic Material Properties

\begin{tabular}{|c|c|c|}
\hline & Material A & Material B \\
\hline Material & $\begin{array}{l}\text { “IRVE”, Calendered, single } \\
\text { sided silicone coated para- } \\
\text { aramid synthetic }\end{array}$ & $\begin{array}{l}\text { Silicone coated plain weave } \\
\text { Kevlar® (200 denier) }\end{array}$ \\
\hline $\mathbf{E}_{1}$ & $\begin{array}{c}\text { 9.78E9 Pa } \\
{[1.42 \mathrm{E} 6 \mathrm{psi}]}\end{array}$ & $\begin{array}{c}\text { 17.7E9 Pa } \\
{[2.57 \mathrm{E} 6 \mathrm{psi}]}\end{array}$ \\
\hline $\mathbf{E}_{2}$ & $\begin{array}{c}4.82 \mathrm{E} 9 \mathrm{~Pa} \\
{[0.70 \mathrm{E} 6 \mathrm{psi}]}\end{array}$ & $\begin{array}{c}15.8 \mathrm{E} 9 \mathrm{~Pa} \\
{[2.30 \mathrm{E} 6 \mathrm{psi}]}\end{array}$ \\
\hline $\mathbf{G}_{12}$ & $\begin{array}{c}17.0 \mathrm{E} 6 \mathrm{~Pa} \\
{[2.47 \mathrm{E} 3 \mathrm{psi}]}\end{array}$ & $\begin{array}{c}1.25 \mathrm{E} 6 \mathrm{~Pa} \\
{[181 \mathrm{psi}]}\end{array}$ \\
\hline$v_{12}$ & 0.51 & 0.46 \\
\hline \multirow[b]{2}{*}{ Source } & Hutchings et al. (2009) & Lin et al. (2010) \\
\hline & $\begin{array}{l}\text { Sun et al. (2005) and Zhu et al. } \\
\text { (2011) for } v_{12}\end{array}$ & $\begin{array}{l}\text { Sun et al. (2005) and Zhu et al. } \\
\text { (2011) for } v_{12}\end{array}$ \\
\hline \multicolumn{3}{|c|}{1 is the warp direction and 2 is the fill direction } \\
\hline
\end{tabular}

Additional assumptions had to be made for assigning the Poisson's Ratio to Materials A and B. The values listed in Table 1 are based on the work of Sun et al. (2005) on comparing theoretically calculated and experimentally obtained properties for polyester, cotton, and wool fabrics, and the work of Zhu et al. (2011) on experimentally measuring the Poisson's Ratio of Kevlar ${ }^{\circledR} 49$ fabric.

\section{FINITE ELEMENT ANALYSIS MODEL}

A quarter of the cruciform geometry was modeled in Abaqus/CAE and the appropriate boundary conditions were applied along the planes of symmetry. An enforced displacement was applied to the ends of the tails to simulate the action of the grips, and displacements in the direction perpendicular to the motion of the grips were constrained to simulate clamping at the grips. This study applied displacement ratios of 1-to-1, 1-to-2, and 2-to-1 in the two orthogonal directions, i.e. the enforced displacements in the $\mathrm{X}$ and $\mathrm{Y}$ directions (warp and fill directions, respectively). The finite element model is shown in Figure 3 for the three L/W (tail length-to-width) ratios. The Abaqus/Standard solver was utilized for the current analyses. 


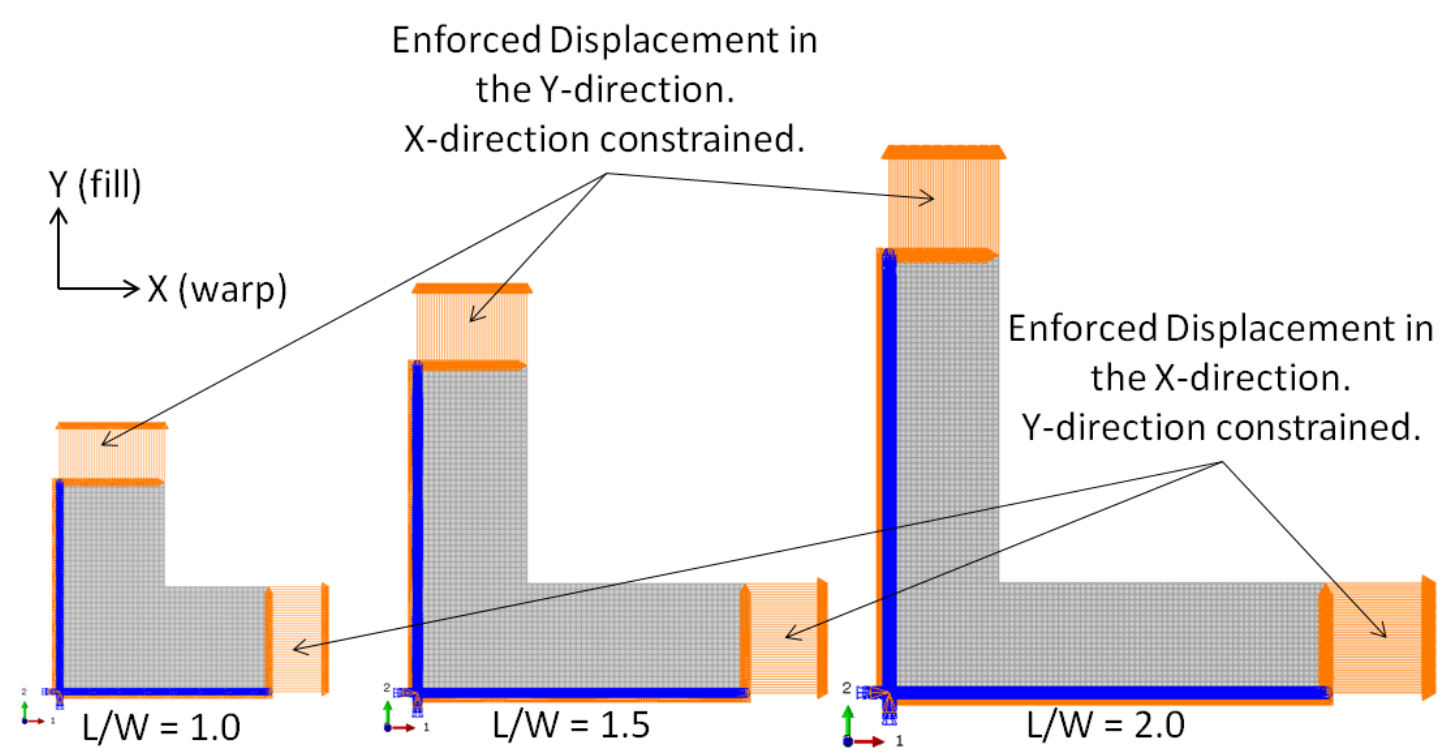

Figure 3. Symmetry models of the three cruciform geometry configurations.

\section{RESULTS}

The resulting reaction load ratios, RX/RY, resulting from the enforced displacement ratios between the $\mathrm{X}$ (warp) and $\mathrm{Y}$ (fill) yarn directions for the various L/W and material combinations are listed on Table 2. Due to the orthotropic material properties, the resultant load ratios do not equal the enforced displacement ratios. Material B's stiffness properties in the warp and fill directions are closer together than that of Material A's, hence Material B's reaction load ratios somewhat better resemble the enforced displacement ratios. On the other hand, Material A's stiffness in the warp direction $\left(\mathrm{E}_{1}\right)$ is about twice that in the fill direction $\left(\mathrm{E}_{2}\right)$, and the resultant reaction load ratios reflect this.

Table 2. Reaction Load Ratios Due To Enforced Displacements.

\begin{tabular}{|c|c|c|c|}
\hline Length-to-Width Ratio: & L/W = 1.0 & L/W = 1.5 & L/W = 2.0 \\
\hline Enforced Displacement Ratio: UX/UY = 1/1 \\
\hline Material A & 1.82 & 1.88 & 1.91 \\
\hline Material B & 1.10 & 1.10 & 1.11 \\
\hline \multicolumn{4}{|l|}{} \\
\hline Enforced Displacement Ratio: UX/UY = 2/1 \\
\hline Material A & 2.84 & 3.15 & 3.33 \\
\hline Material B & 1.69 & 1.83 & 1.91 \\
\hline Enforced Displacement Ratio: UX/UY = 1/2 \\
\hline Material A & 1.13 & 1.09 & 1.07 \\
\hline Material B & 0.71 & 0.66 & 0.64 \\
\hline
\end{tabular}


Per Dawicke and Pollock (1997), a useful method of quantifying the uniformity of the strain distribution in the central square area (as indicated by the dashed boxes in Figure 2) is calculating the strain ratio between the $\mathrm{X}$ (warp) and $\mathrm{Y}$ (fill) directions, $\varepsilon_{\mathrm{x}} / \varepsilon_{\mathrm{y}}$. A single parameter that quantifies the uniformity of the strain distribution is defined as the strain ratio gradient; the strain ratio gradient represents the variation between the highest and lowest strain ratios within the central square area. The strain ratio gradient, reported here as a percentage, is calculated by taking the difference between the highest and lowest strain ratios and dividing it by the highest strain ratio within the central square area.

Figure 4 shows the contour plots of the strain ratios (indicating strain distribution uniformity) for the three length-to-width ratios under an enforced displacement ratio of 1-to-1 for Material A. Under this specific loading condition, increasing the L/W ratio from 1.0 to 2.0 reduces the strain ratio gradient from $0.186 \%$ to $0.129 \%$. Hence, increasing the tail length from that equal to the tail width to twice the tail width promotes strain distribution uniformity by nearly $31 \%$.

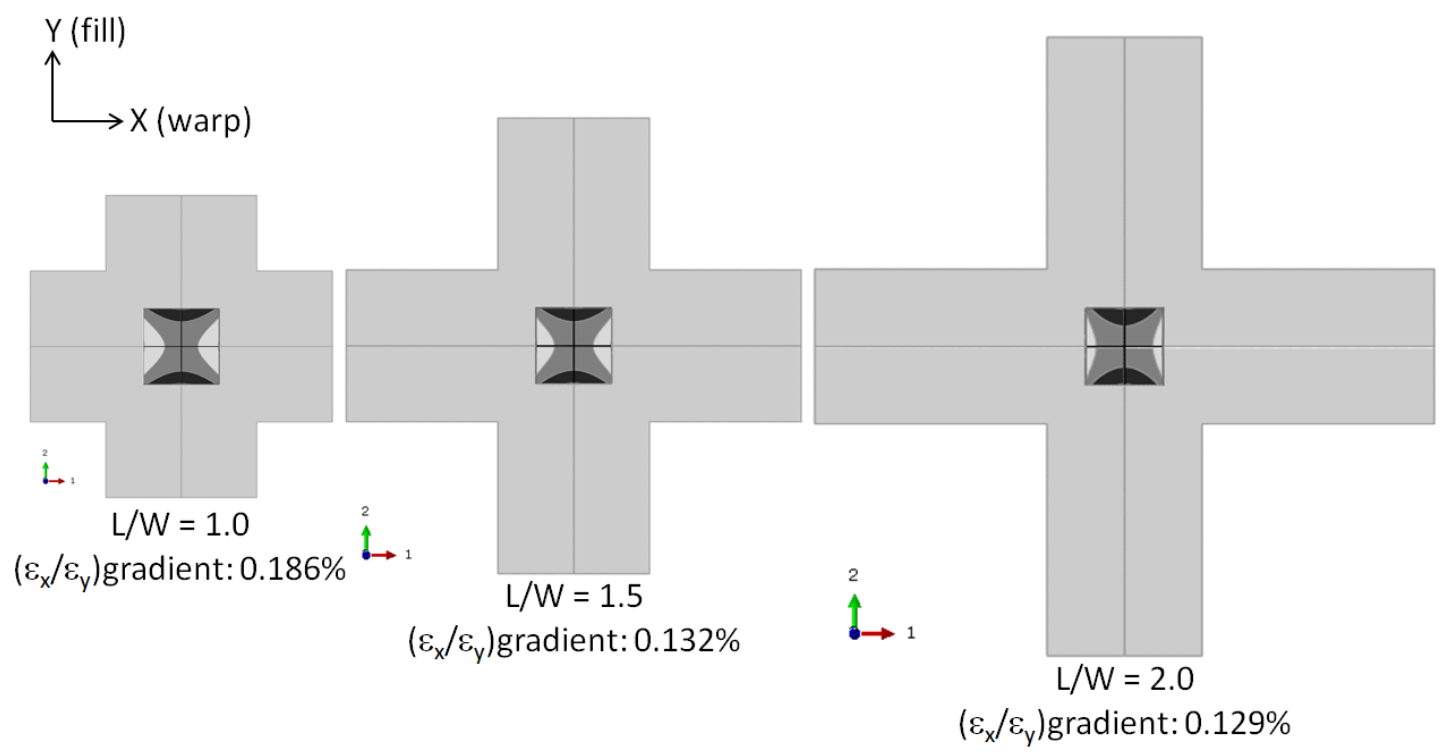

Figure 4. Strain ratio gradients for Material A under 1-to-1 displacement ratio.

The results of all of the tail length-to-width ratio, L/W, enforced displacement ratio, UX/UY, and material combinations are presented in Table 3.

The results in Table 3 are graphically shown in Figure 5, where the gradient values have been normalized with respect to the case for a tail length-to-width ratio, $\mathrm{L} / \mathrm{W}$, of 1.0. A lower value on the $\mathrm{Y}$-axis is better, i.e. greater strain distribution uniformity compared to the baseline tail length-to-width ratio of 1-to-1.

In general, increasing the tail length-to-width ratio increases strain distribution uniformity for Material A, except for the one case where the enforced displacement ratio is 2-1 and length-to-width ratio is 2.0. A significant increase in strain distribution uniformity can be achieved when the enforced displacement ratio 
(between the warp and fill directions) is 1-to-2 or 1-to-1. However, when the enforced displacement ratio is 2-to-1, increasing the tail length-to-width ratio to 2.0 lowers the strain distribution uniformity by approximately $10 \%$ relative to a lengthto-width ratio of 1.0. In contrast, for Material $B$, where the material stiffness in the two orthogonal directions are close (see Table 1), an enforced displacement ratio results in a less uniform strain distribution when the tail length-to-width ratio is increased, except for at the enforced displacement ratio of 1-to-1.

Table 3. Strain distribution uniformity for all variable combinations.

\begin{tabular}{|c|c|c|c|}
\hline Length-to-Width Ratio: & L/W = 1.0 & L/W = 1.5 & L/W = 2.0 \\
\hline Enforced Displacement Ratio: UX/UY = 1/1 \\
\hline Material A & $0.186 \%$ & $0.132 \%$ & $0.129 \%$ \\
\hline Material B & $0.201 \%$ & $0.192 \%$ & $0.190 \%$ \\
\hline \multicolumn{4}{|c|}{} \\
\hline Enforced Displacement Ratio: UX/UY = 2/1 \\
\hline Material A & $0.313 \%$ & $0.295 \%$ & $0.357 \%$ \\
\hline Material B & $0.289 \%$ & $0.328 \%$ & $0.371 \%$ \\
\hline Enforced Displacement Ratio: UX/UY = 1/2 \\
\hline Material A & $0.185 \%$ & $0.131 \%$ & $0.128 \%$ \\
\hline Material B & $0.258 \%$ & $0.274 \%$ & $0.292 \%$ \\
\hline
\end{tabular}

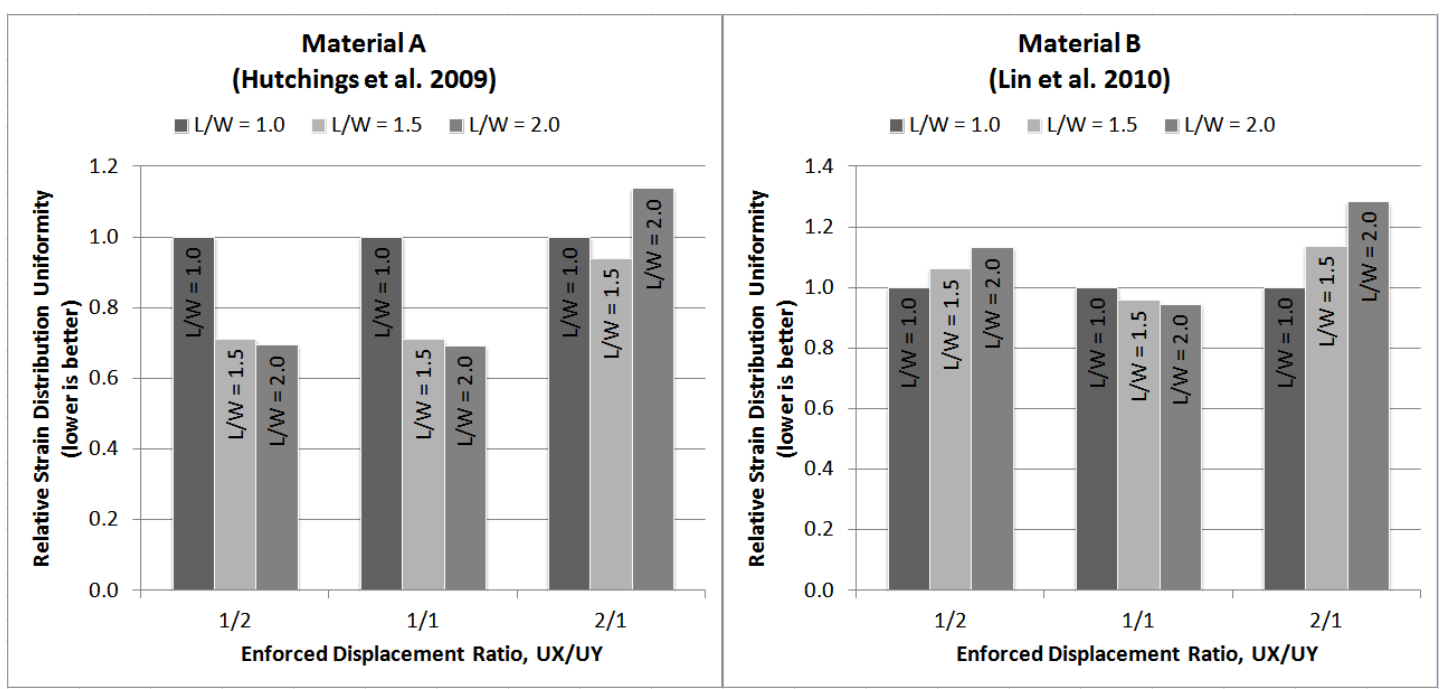

Figure 5. Normalized strain distribution uniformity for Materials A and B.

\section{CONCLUSION}

A preliminary analytical study for quantifying the effects of varying the geometry of a bi-axially loaded cruciform test specimen on the uniformity of the strain distribution was conducted. Depending on the assumed material properties, increasing tail length relative to tail width can either benefit or hinder the strain distribution uniformity. A 
good starting specimen geometry for experimental testing is to make the tail width as wide as possible based on the available gripping/clamping mechanism because this promotes the largest possible central area for which half of it can be relied upon to produce a zone of strain distribution uniformity. The current study suggests that a tail length that is 1.5 times that of the tail width should be the baseline/initial specimen design.

\section{REFERENCES}

Bassett, R. J., Postle, R., and Pan, N. (1999). "Experimental Methods for Measuring Fabric Mechanical Properties: A Review and Analysis,” Textile Research Journal, Vol. 69, 1999, pp. 866-875.

Cavallaro, P. V., Sadegh, A. M., and Quigley, C. J. (2007). “Contributions of Strain Energy and PV-work on the Bending Behavior of Uncoated Plain-woven Fabric Air Beams,” Journal of Engineered Fibers and Fabrics, Vol. 2, No. 1, 2007, pp. 16-30.

Dassault Systémes (2011). Abaqus/CAE and Abaqus/Standard (Version 6.11-1) [Computer software], Providence, Rhode Island.

Dawicke, D.S., and Pollock, W.D. (1997). "Biaxial Testing of 2219-T87 Aluminum Alloy Using Cruciform Specimens,” NASA Contractor Report 4782, August 1997.

Freeston, W. D., Jr., Platt, M. M., and Schoppee, M. M. (1967). "Mechanics of Elastic Performance of Textile Materials, Part XVIII. Stress-Strain Response of Fabrics Under Two-Dimensional Loading,” Textile Research Journal, Vol. 37, 1967, pp. 948-975.

Ghosh, T. K. (1999). "Development and Evaluation of a Biaxial Tensile Tester for Fabrics,” Journal of Testing and Evaluation, JTEVA, Vol. 27, No. 4, July 1999, pp. 282-289.

Hinkle, J. (2010). “ILC Test Lab”, personal communication via email

Hutchings, A. L., Braun, R. D., Masuyama, K., and Welch, J. V. (2009). "Experimental Determination of Material Properties for Inflatable Aeroshell Structures," AIAA Paper AIAA 2009-2949, 20 ${ }^{\text {th }}$ AIAA Aerodynamic Decelerator Systems Technology Conference and Seminar, Seattle, WA, May 4-7, 2009.

Kawabata, S., Niwa, M., and Kawai, H. (1973). “The Finite-Deformation Theory of Plain-Weave Fabrics, Part I: The Biaxial-Deformation Theory,” Journal of The Textile Institute, Vol. 64, 1973, pp. 21-46. 
Klein, W. G. (1959). "Stress-Strain Response of Fabrics Under Two-Dimensional Loading, Part I: The FRL Biaxial Tester,” Textile Research Journal, Vol. 29, 1959, pp. 816-821.

Lin, J. K., Shook, L. S., Ware, J. S., and Welch, J. V. (2010). “Flexible Material Systems Testing, Final Report,” NASA Contractor Report 2010-216854, May 2010.

Lindell, M. C., Hughes, S. J., Dixon, M., and Willey, C. E. (2006). “Structural Analysis and Testing of the Inflatable Re-entry Vehicle Experiment (IRVE),” AIAA Paper AIAA 2006-1699, 47 ${ }^{\text {th }}$ AIAA/ASCE/AHS/ASC Structures, Structural Dynamics, and Materials Conference, Newport, RI, May 1-4, 2006.

Reinhardt, H. W. (1976). "On the Biaxial Testing and Strength of Coated Fabrics,” Experimental Mechanics, Vol. 16, No. 2, February 1976, p. 71-74.

Sebring, R. E., Schoppee, M. M., Freeston, W. D., Jr., and Monego, C. J. (1969). “Test Report: Biaxial Tensile Tests of Coated Fabrics," U.S. Army Natick Laboratories Technical Report 69-75-GP, May 1969.

Sun, H., Pan, N., and Postle, R. (2005). “On the Poisson's Ratios of a Woven Fabric,” Composite Structures, Vol. 68, 2005, pp. 505-510.

Testa, R. B., Stubbs, N., and Spillers, W. R. (1978). "Bilinear Model for Coated Square Fabrics,” Journal of The Engineering Mechanics Division, Vol. 104, 1978, pp. 1027-1042.

Zhu, D., Mobasher, B., and Rajan, S. D. (2011), "Characterization of Mechanical Behavior of Kevlar® 49 Fabrics,” Proceedings of the 2011 Annual Conference on Experimental and Applied Mechanics, Vol. 6, 2011, pp. 377-384. 